Research Article

\title{
A comparative prospective study of preoperative antibiotic prophylaxis in the prevention of surgical site infections
}

\author{
Suresh Karlatti*, I. B. Havannavar
}

Department of Surgery, Belgaum Institute of Medical Sciences, Belgaum, Karnataka, India

Received: 09 October 2015

Accepted: 18 November 2015

\author{
*Correspondence: \\ Dr. Suresh Karlatti, \\ E-mail: suresh_karlatti@rediffmail.com
}

Copyright: $(\odot$ the author(s), publisher and licensee Medip Academy. This is an open-access article distributed under the terms of the Creative Commons Attribution Non-Commercial License, which permits unrestricted non-commercial use, distribution, and reproduction in any medium, provided the original work is properly cited.

\begin{abstract}
Background: Most common cause of post-operative morbidity is surgical site infection (SSI) in planned cases accounting nearly $65 \%$ to $80 \%$ of all cases in our population. Prior to the use of prophylactic antibiotic, the incidence of surgical site infection was more, which has been drastically reduced the incidence of surgical site infection. This study was conducted to know the need for antibiotic prophylaxis in clean, clean-contaminated surgical wounds and whether prophylactic antibiotic is itself sufficient to minimize surgical site infection.

Methods: 300 patients admitted during January 2011 to December 2012 in District hospital Belgaum, attached to Belgaum Institute of Medical Sciences were selected for our study and were subjected for clean or clean contaminated surgeries done under meticulous surgical technique.

Results: Our study showed that there is no need for prophylactic antibiotics in cases of clean surgeries. We recommend antibiotic prophylaxis in clean contaminated cases. The incidence of surgical site infection depends on various factors like old age (21.91\%), anaemia (23.97\%), Diabetes mellitus $(20.54 \%)$ and prolonged duration of surgery more than 2 hours $(14.38 \%)$.

Conclusions: From this study we can conclude that, in cases of clean surgeries there is no need for prophylactic antibiotics, as there is no statistical significance, whereas in clean contaminated cases antibiotic prophylaxis is recommended as it reduces SSI statistically significant.
\end{abstract}

Keywords: Clean, Clean contaminated, Prophylactic antibiotic, Risk factors, Surgical site infection

\section{INTRODUCTION}

Surgical site infection (SSI) is defined as an infection related to an operative procedure that occurs at or near the surgical incision within 30 days of the procedure. ${ }^{1,2}$ The criteria laid by Centers for Disease Control and Prevention (CDC) and the National Nosocomial Infection System is as follows:

1. A purulent exudates draining from a surgical site

2. A positive culture obtained from a surgical site that was closed initially

3. Diagnosis of infection by the surgeon

4. Surgical site showing any one of signs or symptoms like tenderness, swelling, redness, or heat.
Most common cause of post-operative morbidity is surgical site infection (SSI) in planned cases accounting nearly $65 \%$ to $80 \%$ of all cases in our population. ${ }^{3}$ Prior to the use of prophylactic antibiotic, the incidence of surgical site infection was more, which has been drastically reduced by the use of antibiotics. The antibiotic era which began more than 5 decades ago has revolutionized the treatment of surgical infection particularly during post-operative period. To reduce the incidence of post-operative surgical site infection wide spread of use of antibiotics has frequently resulted in unrealistic use of antibiotics, over use of antibiotics and development of resistance to antibiotics. This has resulted in increase in the cost of post-operative treatment and 
violation of established surgical principles and the breakdown of isolation procedures.

Strachan in 1977 compared a single preoperative dose of Cefazolin with regime of Cefazolin given for a period of 5 days post operatively. The infection rate seen in single dose was $3 \%$ and in multiple post-operative dose was $5 \%{ }^{4}$ Hence prophylactic antibiotic therapy is clearly more effective when began preoperatively and continued through the intra operative period with the aim of achieving therapeutic blood levels throughout the operative period.

In the present study we want to emphasize on the role of antibiotic prophylaxis administration in clean and cleancontaminated surgical cases in this institution.

The aim was to study the use of prophylactic antibiotic in clean, clean-contaminated surgical wounds and whether prophylactic antibiotic itself is sufficient to minimize surgical site infection.

\section{METHODS}

This was a prospective study consisting of cases admitted to our District hospital attached to Belgaum Institute of Medical Sciences, Belgaum from January 2011 to December 2012 for a period of 2 years. During this period, 300 cases were selected for our study. The cases were grouped in to two categories; Group A and Group B of 150 cases each. Group A comprises patients who received a pre-operative single dose of ceftriaxone a broad spectrum cephalosporin. Group B received no such prophylactic antibiotic. The groups were split randomly into two groups taking into consideration the type of surgeries, the age of the patient, the presence or absence of risk factors for development of SSI, and associated medical conditions, all of which were represented in both the groups almost equal and a comparative clinical study was made. All were subjected to surgeries done under meticulous surgical technique.

On admission to the hospital, a detailed proforma was filled with details like the diagnosis, preoperative investigations and meticulous pre-operative patient preparation. All the patients were followed up to thirty days post operatively. Data were entered in the proforma. Wound swabs were sent for culture and sensitivity and the patients were treated according to culture and sensitivity reports. Patients were categorized as clean or clean contaminated cases depending on their complaints, clinical examination and diagnosis. Patients with infections like respiratory tract infections or urinary tract infections were treated prior to admission on out-patient basis and taken up for surgery after 2 weeks. All patients were admitted 2 days prior to surgery. Preoperative hospital stay was minimized to prevent the patient from getting the access to hospital infections. Patients with diabetes mellitus were treated appropriately with injectable insulin under precaution.

Preoperative skin preparation was done meticulously. Patients allowed to take a through scrub bath after which parts were prepared with povidone iodine and was isolated from the surrounding by covering operative site by sterile gauze. ${ }^{6}$ Patients were brought to the waiting room next day morning and were given single dose of IV ceftriaxone $1 \mathrm{gm}$ under aseptic precaution half an hour before the surgery. All the cases were done in the morning hours. Patients were anesthetized under aseptic precaution. Sterile gauze was removed and patient's skin was painted with povidone iodine solution and sprit. Then the surface was allowed to dry. Then it was covered with sterile towels and sheets. Surgery was performed by senior staff, use of cautery was minimized. Movement in the operating room was restricted. Whenever necessary closed suction drain was introduced and wound was closed with sterile dressings.

Patients were isolated in the postoperative ward for at least 3 days. Drains were removed on $3^{\text {rd }}$ or $4^{\text {th }}$ postoperative day depending upon the secretions. Wounds were inspected on third day for any signs of inflammation, infection was noted down and findings were entered in the proforma. In cases where soakage of dressing and abnormal smells suggestive of infection dressings were inspected earlier than 3 days. If infected, wound swab was taken and sent for culture and sensitivity and antibiotic was started immediately in all infected cases. Sutures were removed on the seventh postoperative day. Patients were followed up to thirtieth postoperative day on OPD basis after discharged from hospital. All the data were entered in the proforma. The available results and outcomes in both groups were studied and analyzed and then they were compared with the previous studies and final conclusion was drawn.

\section{RESULTS}

The present study consists of 300 clean and clean contaminated elective surgical cases admitted to District hospital attached to Belgaum Institute of Medical Sciences, Belgaum from January 2011 to December 2012 for a period of 2 years, were divided equally into two groups, Group A included 150 cases who received single prophylactic dose of $1 \mathrm{gm}$ of cefotriaxone given intravenously half an hour before surgery and Group B included 150 cases who did not receive any such antibiotic prior to surgery.

The incidence of age varied from 5 to 60 years but maximum number of patients belonged to 21 to 30 years age group. Six patients in group B were infected; one belonged to 41-50 years age group three belonged to the 51-60 years age group and other two in the 61-70 years age group. 
Table 1: Infection rates in all cases.

\begin{tabular}{|lllllll|}
\hline & \multicolumn{2}{c}{ Number of cases } & \multicolumn{2}{c|}{$\begin{array}{c}\text { Number of cases which got } \\
\text { infected }\end{array}$} & \multicolumn{2}{c|}{ Rate of infection } \\
\hline & Clean & Clean contaminated & Clean & Clean contaminated & Clean & Clean contaminated \\
\hline Group A & 105 & 45 & - & - & - & - \\
\hline Group B & 100 & 50 & 4 & 20 & $4 \%$ & $34 \%$ \\
\hline Total & 205 & 95 & 4 & 20 & $1.95 \%$ & $21.05 \%$ \\
\hline
\end{tabular}

\section{Infection rate}

Group A had 105 clean surgical cases and 45 clean contaminated cases, out of which none of them were infected. In group B out of 100 clean cases, 4 cases were infected and out of 50 clean contaminated cases 20 were infected.

\section{Risk factors}

Out of 300 cases taken up for the study 118 patients were identified to have risk factors for development of surgical site infection. The incidence and distribution of risk factors is as follows.

Table 2: Showing distribution of risk factors in the affected group.

\begin{tabular}{|c|c|c|c|c|}
\hline $\begin{array}{l}\text { Risk } \\
\text { Factors }\end{array}$ & $\begin{array}{l}\text { Group } \\
\text { A }\end{array}$ & $\begin{array}{l}\text { Group } \\
\text { B }\end{array}$ & Total & $\begin{array}{l}\text { Percentage } \\
(\%)\end{array}$ \\
\hline Anaemia & 15 & 20 & 35 & $29.67 \%$ \\
\hline $\begin{array}{l}\text { Diabetes } \\
\text { Mellitus }\end{array}$ & 12 & 18 & 30 & $25.42 \%$ \\
\hline $\begin{array}{l}\text { Prolonged } \\
\text { duration } \\
\text { of surgery }\end{array}$ & 0 & 21 & 21 & $17.79 \%$ \\
\hline Old age & 14 & 18 & 32 & $27.12 \%$ \\
\hline Total & 41 & 77 & 118 & 100 \\
\hline
\end{tabular}

In the our study 35 patients were suffering from mild anemia with $\mathrm{Hb} \%$ between $9-10 \mathrm{gr} \%, 15$ patients in group A and 20 in group B. The 30 patients with diabetes mellitus, 12 in group A and 18 in group B, their sugar levels were controlled prior to surgery, none of them developed SSI. 35 patients with anemia which was corrected prior to surgery did not develop SSI. Out of 32 patients with old age 12 developed SSI, these 12 had other associated risk factors.

\section{Duration of surgery}

All the cases in this study were clean and clean contaminated elective surgeries conducted by senior staff. Care was taken to complete the surgery as early as possible and efficiently. The average duration of the surgery in our study from the time of skin incision to the time of closure was 1 hour 40 minutes. The minimum time was 45 minutes and maximum time was two hours fifteen minutes. Six patients in our study who got infected the duration was 1 hour and 55 minutes and the other 12 patients who got infected the duration was more than two hours. No patients whose surgery was done below one hour got infected in both the groups.

Table 3: Showing duration of surgery affecting infection rate.

\begin{tabular}{|c|c|c|c|c|}
\hline \multirow{2}{*}{$\begin{array}{l}\text { Duration } \\
\text { in } \\
\text { hours }\end{array}$} & \multicolumn{2}{|c|}{$\begin{array}{l}\text { Number of } \\
\text { cases }\end{array}$} & \multirow{2}{*}{$\begin{array}{l}\text { Number } \\
\text { of } \\
\text { infected } \\
\text { cases }\end{array}$} & \multirow{2}{*}{$\begin{array}{l}\text { Percentage } \\
\text { of } \\
\text { infection }\end{array}$} \\
\hline & $\begin{array}{l}\text { Group } \\
\text { A }\end{array}$ & $\begin{array}{l}\text { Group } \\
\text { B }\end{array}$ & & \\
\hline$<1$ hour & 105 & 90 & - & - \\
\hline 1-2 hours & 45 & 42 & 6 & $14.28 \%$ \\
\hline$>2$ hours & 0 & 18 & 12 & $66.66 \%$ \\
\hline
\end{tabular}

\section{Drains}

In the present study 90 patients were provided with closed suction drainage and none of them got infected, contributing to the use of closed suction drainage to prevent surgical wound infection rather than the open drainage method.

Table 4: Showing infection rate with and without prophylactic antibiotics in clean and clean contaminated cases.

\begin{tabular}{|lllll|}
\hline $\begin{array}{l}\text { Type of } \\
\text { case }\end{array}$ & Groups & $\begin{array}{l}\text { Number } \\
\text { of cases }\end{array}$ & $\begin{array}{l}\text { Number } \\
\text { of } \\
\text { infected } \\
\text { cases }\end{array}$ & $\begin{array}{l}\text { Percent } \\
\text { age }\end{array}$ \\
\hline Clean & Group A & 105 & - & - \\
\cline { 2 - 5 } & Group B & 100 & 4 & $1.46 \%$ \\
\hline $\begin{array}{l}\text { Clean } \\
\text { Contami } \\
\text { nated }\end{array}$ & Group A & 45 & - & $17.89 \%$ \\
\cline { 2 - 5 } & Group B & 50 & 17 & 17 \\
\hline
\end{tabular}

\section{Antibiotic and timing of antibiotic prophylaxis}

In the present study a third generation cephalosporin's single dose of IV ceftriaxone $1 \mathrm{gm}$ was administered half an hour before the incision under aseptic precaution to all the patients in group A and no patients in group A got infected when compared to the group B, where no such antibiotic was given and there was an infection rate of $3.80 \%$ (4 patient) in clean cases and $37.78 \%$ (17 patients) 
in clean contaminated cases. There were no reports of any allergy and adverse effects to the prophylactic drug chosen.

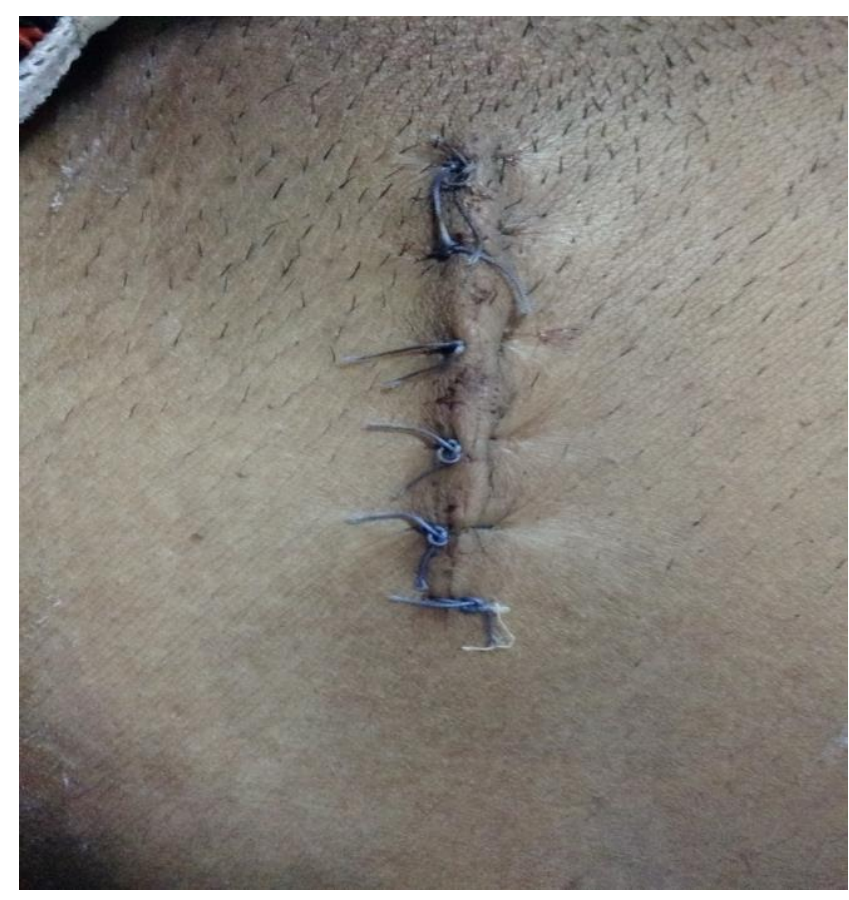

Figure 1: Showing mild infection with redness on the $3^{\text {rd }}$ day of operation.

\section{DISCUSSION}

Surgical site infection is well known thing. This has been documented since origin of surgery. Strict asepsis, meticulous surgical techniques, less handling of tissues, reducing the use cautary and use of prophylactic antibiotic have drastically reduced the incidence of SSI.

\section{Age incidence}

Surgical site infection affects all the age groups and its incidence increases with the age. In our present study age incidence varied from 5 to 60 years but the maximum number of cases were represented in age group 21- 30 years.

Older age group is considered a risk factor for development of SSI, in the present study all the 10 infected cases were 50 years and above age group and two cases in 41-50 years age group. Rao et al showed in their study that SSI incidence doubled in older age group $50-70$ years. ${ }^{6}$

\section{Role of risk factors}

18 cases had prolonged duration of surgery, six cases it was 1 hour and 50 minutes, rest all 12 cases it was more than 2 hours. Here 32 cases belonged to old age group (14 in A and 18 in B group) were infected. It can be said from the present study that presence of more than one risk factor has a significant impact on the development of surgical site infection and they were at definite risk of developing SSI when they are not given prophylactic antibiotic dose. Cruise and Ford have demonstrated that presence of obesity as a single independent risk factor for development of SSI and the prolonged time of surgery also increase the incidence of surgical site infection. ${ }^{8}$ Anemia was present in 35 patients all the 35 patients were treated preoperatively for correction of anemia. Their hemoglobin levels were corrected prior to surgery and then taken up for surgery. 15 in group A and 20 in group B and none of them developed surgical site infection. Hence anemia when corrected preoperatively does not pose a risk for development of surgical site infection.

In the present study, 30 patients were diabetic (group A12, Group B-18) their blood sugar level was well controlled prior, during and after surgery. Funary AP et al in their study showed that when blood glucose level were kept strictly below $200 \mathrm{mg} / \mathrm{dl}$ during the perioperative period by continuous intravenous infusion of insulin reduced the incidence of SSI from $24 \%$ to $6.06 \%$ which was statistically significant. ${ }^{9}$ As none of the patients developed SSI and hence it is said that infection rate can be reduced with the proper control of diabetic status.

\section{Types of surgery undertaken}

The type of surgery undertaken had significant role in development of SSI. The different studies in accordance with our study are as follows:

Table 5: Types of surgeries and infection rate.

\begin{tabular}{|llll|}
\hline Studies & Clean & $\begin{array}{l}\text { Clean- } \\
\text { Contaminated }\end{array}$ & Contaminated \\
\hline Lilani et al $^{10}$ & $3.68 \%$ & $22.4 \%$ & $32.45 \%$ \\
\hline Cruse et al & $7 \%$ & $18 \%$ & $35 \%$ \\
\hline $\begin{array}{l}\text { Present } \\
\text { study }\end{array}$ & $1.95 \%$ & $21.05 \%$ & - \\
\hline
\end{tabular}

Out of total 300 cases 205 were clean and 95 cleancontaminated surgical cases.

Table 6: Comparison of wound infection rate in relation to the duration of operation.

\begin{tabular}{|c|c|c|c|}
\hline \multicolumn{4}{|c|}{ Time in Hours } \\
\hline & 1 Hours & 1-2 Hours & $>2$ Hours \\
\hline Cruise and Ford $^{8}$ & $1.4 \%$ & $1.8 \%$ & $4.4 \%$ \\
\hline Lilani et al $^{10}$ & - & $1.47 \%$ & $38.46 \%$ \\
\hline Present Study & - & $14.28 \%$ & $66.66 \%$ \\
\hline
\end{tabular}

\section{Duration of surgery}

Various studies indicate that there is a direct relationship between the length of the operating time and the rate of 
infection of clean wounds roughly double with every hour of operating time and is as shown in the various studies done previously in the Table 6 .

Thus our study proves that there is a direct relationship between the length of the operating time and infection rate, the rate of infection of clean wounds roughly double with every hour of operating time. The explanation of high infection rate in $>2$ hours group in the present study is probably because of the small number of cases in that group.
In the present study the use of third generation cephalosporin, single dose of IV ceftriaxone $1 \mathrm{gm}$ is justified and having a prolonged half-life up to 8 to 12 hours which will take care of the wound in its initial crucial phase. It was administered half an hour before the incision under aseptic precaution to all the patients in group A and no patients in group A got infected when compared to the group B, where no such antibiotic was given and there was an incidence of infection rate of $8.33 \%$ (4 patients from clean surgeries and 20 from clean-contaminated surgeries were infected).

\section{Antibiotic and timing of antibiotic prophylaxis}

Table 7: The present study is compared with that of the similar studies conducted in the past for clean cases.

\begin{tabular}{|llllll|}
\hline Study & $\begin{array}{l}\text { No antibiotic } \\
\text { administered, } \\
\text { Number of patients }\end{array}$ & $\begin{array}{l}\text { Percentage of } \\
\text { infections }\end{array}$ & $\begin{array}{l}\text { Prophylactic antibiotic } \\
\text { administered, Number } \\
\text { of patients }\end{array}$ & $\begin{array}{l}\text { Percentage of } \\
\text { infections }\end{array}$ & P value \\
\hline Carlson et al $^{11}$ & 58 & $24.1 \%$ & 60 & $3.3 \%$ & Not significant \\
\hline Rao et al $^{6}$ & 100 & $2.3 \%$ & 100 & $2.86 \%$ & Not significant \\
\hline Present study & 100 (clean cases) & $1.95 \%$ & 105 & 0 & $\mathrm{P}=0.032$ \\
\cline { 2 - 6 } & 50(clean contaminated) & $21.05 \%$ & 45 & 0 & $\mathrm{P}=0.365$ \\
\hline
\end{tabular}

In the present study the overall incidence of infection in the study group B was $1.95 \%$ compared to be nil in group A for clean cases was found to be non significant $(\mathrm{P}=$ $0.3207)$ and $21.05 \%$ in clean contaminated cases which was found to be significant $(\mathrm{P}=0.365)$.

\section{CONCLUSION}

From this study we can conclude that, in cases of clean surgeries there is no need for prophylactic antibiotics, as there is no statistical significance, whereas in clean contaminated cases antibiotic prophylaxis is recommended as it reduces SSI statistically significant.

Funding: No funding sources

Conflict of interest: None declared

Ethical approval: The study was approved by the institutional ethics committee

\section{REFERENCES}

1. Anderson DJ, Sexton DJ. Epidemiology and pathogenesis of and risk factors for surgical site infection. Up-to-date. 2008. http://www. uptodate.com.

2. Mangram AJ, Horan TC, Pearson ML, Silver LC, Jarvis WR. Guideline for prevention of surgical site infection: 1999. Hospital Infection Control Practices Advisory Committee. Infect Control Hosp Epidemiol. 1999;20(4):250-78.

3. Lewis RT, Klein H. Risk factors and post-operative sepsis: Significance of preoperative lymphocytopenia. J Surg Res. 1975;26:365-71.
4. Strachan CJ, Black JP. Prophylactic use of Cefazolin against sepsis after cholecystectomy. British Journal of Medicine. 1977;1:1254-7.

5. Page CP, Bohnen JM, Fletcher JR. Antimicrobial prophylaxis for surgical wounds: Guidelines for clinical care. Arch Surg. 1993;128:79-88.

6. Rao AS, Harsha M. Post-operative wound infection. J India Med Assoc. 1975;44:90-3.

7. Hamilton HW, Hamilton KR, Lone FJ. Preoperative hair removal. The Canadian Journal of Surgery. 1997;20:269-75.

8. Cruise PJE, Foord R. A five year prospective study of 23,649 surgical wounds' Archives of surgery. 1913;107:206.

9. Funary AP, Zerc KJ, Grunkemeier GC, Starr A. Continuous intravenous insulin infusion reduces the incidence of deep sterna wound infection in diabetic patients after cardiac surgical procedures. Ann Thorac Surg. 1999;67:352-60.

10. Lilani, Jangale N. Department of microbiology, Department of surgery, Grant medical college, Byculla , Mumbai. Indian J Surg. 1997;90-3.

11. Carlson GE, Gonnlanakis C, Tsatsakis A. Preincisional single dose ceftriaxone for prophylaxis of surgical wound. American Journal of Surgery. 1995;170(4):353-5.

Cite this article as: Karlatti S, Havannavar IB. A comparative prospective study of preoperative antibiotic prophylaxis in the prevention of surgical site infections. Int Surg J 2016;3:141-5. 